\title{
Bioanalysis
}

\section{Evaluation of an FcRn affinity chromatographic method for IgG1-type antibodies and evaluation of IgG variants}

\begin{abstract}
Aim: The neonatal Fc-receptor (FcRn) mediates long serum half-life of therapeutic IgG-type antibodies. This interaction represents a critical quality attribute in terms of pharmacokinetics and should be covered by respective quality control strategies. Antibodies are taken up by cells unspecifically and can bind to FcRn in early endosomes preventing lysosomal degradation and allowing release back into circulation. Reflecting this complex cycle in an in vitro assay strategy represents a challenging task. Methodology: We report the qualification of an FcRn affinity chromatographic method and, for the first time, establish a noncriticality window. We analyzed different IgG-type antibodies, subtypes, glycoforms as well as mutants. Conclusion: The FcRn affinity chromatographic method allows the assessment of mAb samples with respect to their pH-dependent FcRn interaction. Furthermore, the method's capabilities and current limitations are discussed.
\end{abstract}

First draft submitted: 15 May 2017; Accepted for publication: 18 July 2017;

Published online: 12 September 2017

Keywords: affinity chromatography $\bullet \mathrm{FcRn} \bullet \operatorname{lgG}$ pharmacokinetics $\bullet$ monoclonal antibodies

Binding of IgG-type antibodies to the neonatal Fc-receptor $\left(F_{c} R n\right)$ is responsible for the long serum half-life of this subclass of antibodies [1], making them suitable scaffolds for use as therapeutic proteins [1-3]. The complex binding behavior of IgG-type antibodies is due to the recycling function of FcRn. Antibodies are taken up into cells in an unspecific manner by pinocytosis. At the low $\mathrm{pH}$ of early endosome vesicles, IgG-type antibodies can bind in a $\mathrm{pH}$-dependent manner to FcRn and are later recycled back to the cell surface, rather than being degraded in the lysosome. Once the recycling vesicle fuses with the plasma membrane, dissociation of the antibody from FcRn can occur at neutral $\mathrm{pH}$ of the serum/blood.

It has been recognized recently that binding to FcRn at low $\mathrm{pH}$ and dissociation from FcRn at neutral $\mathrm{pH}$ appear to be critical for the reported long FcRn-dependent serum halflife of IgG-type antibodies [4-6]. Since both events are critical components of the FcRn-
IgG interaction, they should be included in a comprehensive analytical strategy as part of the candidate selection, quality control of therapeutic monoclonal antibodies (mAbs) or during quality by design studies [7-9]. Binding of $\mathrm{IgG}$ antibodies at low $\mathrm{pH}$ to FcRn is often characterized by surface plasmon resonance (SPR) binding assays [10-13]. Nevertheless, changes in FcRn binding measured by SPR did not correlate well with changes in serum half-life [14]. Until recently, the pH-dependent dissociation from FcRn was not covered by suitable in vitro assays but could be captured accurately by respective pharmacokinetic (PK) measurements in huFcRn-transgenic mice $[15,16]$.

Recently, FcRn affinity chromatography has been established as a potential surrogate for in vivo studies [4,17-18] and as a suitable complementation of the low $\mathrm{pH}$-binding assays including SPR-based assays. Besides the advantage of the chromatographic FcRn
Florian Cymer*,1, Tilman Schlothauer ${ }^{2}$, Alexander Knaupp 2 \& Hermann Beck ${ }^{1}$ 'Pharma Technical Development Analytics Biologics, F.

Hoffmann-La Roche Ltd, 4070 Basel, Switzerland

${ }^{2}$ Biochemical \& Analytical Research, Large Molecule Research, Roche Pharma Research \& Early Development (pRED), Roche Innovation Center, 82377 Penzberg, Germany *Author for correspondence: florian.cymer@roche.com newlands press part of 
method over SPR-based assays to separate antibody species with different binding behavior [17], this FcRn chromatographic method was also able to reflect differences in in vivo clearance by changes in retention time due to charged patches in the fragment antigen-binding (Fab) region [4]. Additionally, FcRn chromatography was recently used to confirm differences observed between two different SPR setups yielding contradictory binding results [19] and separation by an FcRn column was used in combination with native LC-ESI-MS to characterize modified mAbs [20]. Due to the broad applicability of the method as demonstrated by analysis of Fc-methionine oxidation [18] and different FcRn engineering and charges $[4,17]$, it can be used during extended characterization, screening campaigns and developability assessments. Due to the novelty of the method, no qualification has been performed in the past. Therefore, assay suitability should be established beforehand in a set of qualification experiments. Furthermore, the evaluation method and the respective results should be discussed in the context of their biological relevance, especially in the case of complex binding behaviors as it is the case for FcRn.

Here, we report an FcRn affinity chromatographic HPLC method and its profound qualification for an exemplary IgG1 mAb. Compared with previous usage of FcRn chromatography [4,17-21], we establish, for the first time, a noncriticality window using relative retention times to established standards and include several other technical method improvements. Additionally, we report the FcRn chromatography of different $\mathrm{IgG1}$ antibodies, different IgG subtypes, glycoforms and mutants as well as their evaluation using the method described herein. Besides establishing a suitable HPLC method, we analyze and discuss well-characterized IgG variants in order to relate the chromatographic results in a biologically relevant context.

\section{Materials \& methods}

\section{FcRn column}

FcRn prelaunch column was purchased from Roche Custom Biotech (Mannheim, Germany; cat. no. 08128057001). In the following, the column generation is outlined briefly. The $\alpha$-subunit of human FcRn containing a histidine-avidin tag associated with $\beta-2$ microglubulin (3 $\mathrm{mg}$ of $\mathrm{FcRn}$ complex in total) was biotinylated using BirA biotin-protein ligase kit (Avidity, Aurora, CO, USA; cat. no. bulk BirA) according to manufacturer's instructions. Following dialysis, biotinylated FcRn was washed in $20 \mathrm{mM}$ 2-(N-morpholino)ethanesulfonic acid (MES), $140 \mathrm{mM} \mathrm{NaCl}$ buffer at $\mathrm{pH} 5.5$ (buffer A). The complex was subsequently immobilized onto $1 \mathrm{ml}$ sepharose streptavidin beads (GE Healthcare, Little Chalfont, UK; cat. no. 17-5113-01) via biotin/ streptavidin interaction. The receptor bound beads were then filled in a $4.6 \times 50 \mathrm{~mm}$ chromatographic column (GE Healthcare, Tricorn 5/50 column, cat. no. 28-406409) and were used for chromatographic experiments. The column was stored in $80 \%$ buffer A and $20 \%$ buffer B (20 mM Tris(hydroxymethyl)aminomethane $\mathrm{pH}$ 8.8, $140 \mathrm{mM} \mathrm{NaCl})$. All chemicals were purchased from Sigma (Munich, Germany) unless declared otherwise.

\section{Antibodies \& reagents}

Intravenous immunoglobulin (IVIG) (Subcuvia; Baxter, Vienna, Austria) was used as a standard, since it constitutes a representative pool of $\operatorname{IgG}$ subtypes from at least 1000 individuals. Additionally, an oxidized IgG1 subtype antibody was used as a standard, since it has previously been used during FcRn affinity chromatography ( $\mathrm{mAbl}$ ) and generated $\mathrm{PK}$ data in mice transgenic for human FcRn [17]. Since the isolated peaks have been used previously for in vivo clearance studies, the respective peaks were used to define a noncriticality retention time window and served as borders for system suitability criterion (described under results). The HPLC method was qualified for a generic IgG1 antibody (mAb_A).

A set of IgGK subtypes from human myeloma plasma was purchased from Sigma. In vitro glycoengineering (IVGE) was performed as described previously [22,23]. The IVGE antibodies ( $\mathrm{mAb} \_\mathrm{B}$ and $\mathrm{mAb}$ _C) were standard IgG1 antibodies (with no glycosylation in the Fab region). mAb_B starting material contained a standard chinese hamster ovary $(\mathrm{CHO})$-derived glycopattern, whereas mAb_C starting material contained high levels of bisected, afucosylated glycostructures in its Fc-region (about 70\%) due to use of an engineered cell line. All IVGE samples contained the stated glycostructure to a degree $>95 \%$ (as determined by HPLC analysis after 2-AB labeling). The YTE mutants [24] of $m A b \_D$ and $m A b \_E$ were produced in house, whereas mAb_B N434W [5] mutant was produced by Absolute Antibody (Oxford, UK). Antibodies mAb_F, mAb_G, $\mathrm{mAb} \_\mathrm{H}$ and $\mathrm{mAb} \_\mathrm{I}$ were regular nonmodified IgG1type antibodies, produced in house. All chemicals were purchased from Sigma unless declared otherwise.

\section{Antibody oxidation}

The oxidizing agent tert-Butylhydroperoxide was added to $m A b \_$A reference material to yield a final tert-Butylhydroperoxide concentration of $0.02 \% \mathrm{v} / \mathrm{v}$. Oxidation was allowed to proceed for $2 \mathrm{~h}$. The oxidation reaction was then quenched by addition of a solution of $250 \mathrm{mM}$ L-methionine to yield a final concentration of $50 \mathrm{mM}$. Removal of residual oxidizing agent was accomplished by using sephadex columns (NAPTM5, GE Healthcare). Following purification, protein concentration was determined spectroscopically by measuring the overall 
protein absorbance at $280 \mathrm{~nm}$ and using the respective extinction coefficient. To determine the impact of a composition effect in differently oxidized $\mathrm{mAbl}$, the same oxidation protocol was used using different incubation times, in which case $\mathrm{H}_{2} \mathrm{O}_{2}$ was used as an oxidizing agent. All chemicals were purchased from Sigma unless declared otherwise.

\section{General method description}

The FcRn affinity column was used on a Waters ${ }^{\circledR}$ 2695 separation module 'Alliance' (Waters AG, Switzerland) with in-line vacuum degasser. Absorbance at $280 \mathrm{~nm}$ was used for detection. The autosampler was set to a temperature of $5^{\circ} \mathrm{C}$. The column temperature was at $25^{\circ} \mathrm{C}$. Prior to injection of standards and samples, running buffer was injected until a stable baseline was obtained. In the used method and until stated otherwise, $30 \mu \mathrm{g}$ of standards and samples were subsequently injected in separate runs onto the FcRn column in a volume of $50 \mu \mathrm{l}$ running buffer $\mathrm{A}$. The 100 min continuous gradient to $100 \%$ buffer $B$ was applied with a flow rate of $1 \mathrm{ml} / \mathrm{min}$ (see Table 1). The column was regenerated using buffer A after each run. mAbl and IVIG standards were injected at the beginning and the end of the chromatographic sequence (bracketing). Additional standards were injected if more than 10 samples were run within one sequence. Chromatograms were obtained and processed using Waters Empower software (Waters AG, Baden, Switzerland). Using the method described herein, approximately 150 injections of samples and standards were performed per FcRn column before system suitability criteria (see 'Results' section) were no longer met. Once these criteria were no longer met, the column was discarded and a new column was used.

\section{Data analysis}

Isolated prepeak I (single oxidized M252) and main peak (nonoxidized M252) of oxidized mAb1 standard (see Figure 1 for peak assignment) have previously been shown to have comparable clearance to nonoxidized
mAbl in mice transgenic for human FcRn [18]. It is therefore proposed to regard the retention time interval between prepeak I and main peak as noncritical in terms of FcRn-dependent clearance (noncriticality window). Conservatively, species eluting outside this range are regarded as potentially critical in terms of FcRn-dependent clearance. For evaluation purposes, an arbitrary value of 0 was assigned to oxidized $\mathrm{mAbl}$ prepeak I, whereas an arbitrary value of 1 was assigned to oxidized mAb1 main peak. By applying the following formula, (potential) criticality for FcRn-dependent clearance $\left(\mathrm{C}_{\mathrm{FcRn}}\right)$ is calculated as:

$\mathrm{C}_{\mathrm{FcRn}}=\left(\mathrm{RT}_{\mathrm{SP}}-\mathrm{RT}_{\mathrm{PP} 1}\right) /\left(\mathrm{RT}_{\mathrm{MP}}-\mathrm{RT}_{\mathrm{PP} 1}\right)$

Whereas $\mathrm{RT}_{\mathrm{MP}}$ and $\mathrm{RT}_{\mathrm{PP} 1}$ represent the retention times (in minutes) of oxidized mAb1 main peak and prepreak I, respectively. $\mathrm{RT}_{\mathrm{SP}}$ represents the retention time of a sample peak (in minutes). As a system suitability criterion, IVIG major peak was required to have a $\mathrm{C}_{\mathrm{FcRn}}$ value of $0.5 \pm 0.2$. Outside these limits, the column was shown to give unreliable results and therefore is regarded to be at the end of its lifetime and was replaced.

\section{Results}

Typical chromatograms of standards

Typical chromatograms for oxidized $\mathrm{mAb} 1$ [18] and IVIG as standards are shown in Figure 1, on which fully oxidized mAb1 (both heavy chains M252 are oxidized) elutes as prepeak II, partially oxidized mAb1 (only one heavy chain M252 is oxidized) elutes as prepeak I and intact mAb1 (no heavy chain M252 is oxidized) elutes as the main peak. The latter two are used for evaluation purposes. The possible effect of varying oxidation incubation times on $\mathrm{mAbl}$ peak retention time shifts was tested (see Supplementary Figure 1). The absolute retention times of main peak, prepeak I and prepeak II did not shift significantly over the observed oxidation time of $8 \mathrm{~h}$ although individual peak areas varied to a larger extent.

IVIG major peak elutes at a calculated $\mathrm{pH}$ of approximately 7.4 . Early peaks at around $1-2 \mathrm{~min}$

\section{Table 1. Chromatographic program used for neonatal Fc-receptor affinity chromatography.}

\begin{tabular}{|lll|}
\hline Time (min) & \% Mobile phase A & \% Mobile phase B \\
\hline 0 & 100.0 & 0.0 \\
5 & 100.0 & 0.0 \\
\hline 105 & 0.0 & 100.0 \\
\hline 110 & 0.0 & 100.0 \\
111 & 100.0 & 0.0 \\
\hline 115 & 100.0 & 0.0 \\
\hline $\begin{array}{l}\text { The column was run for } 5 \text { min in buffer A after sample injection, followed by a continuous gradient of } 100 \text { min to buffer B. The column was } \\
\text { then washed for } 5 \text { min in buffer B, changed within } 1 \text { min to 100\% buffer A and run at 100\% buffer A for four more minutes. The flow rate } \\
\text { was constant at } 1 \mathrm{ml} / \mathrm{min} .\end{array}$ \\
\hline
\end{tabular}


Methodology Cymer, Schlothauer, Knaupp \& Beck

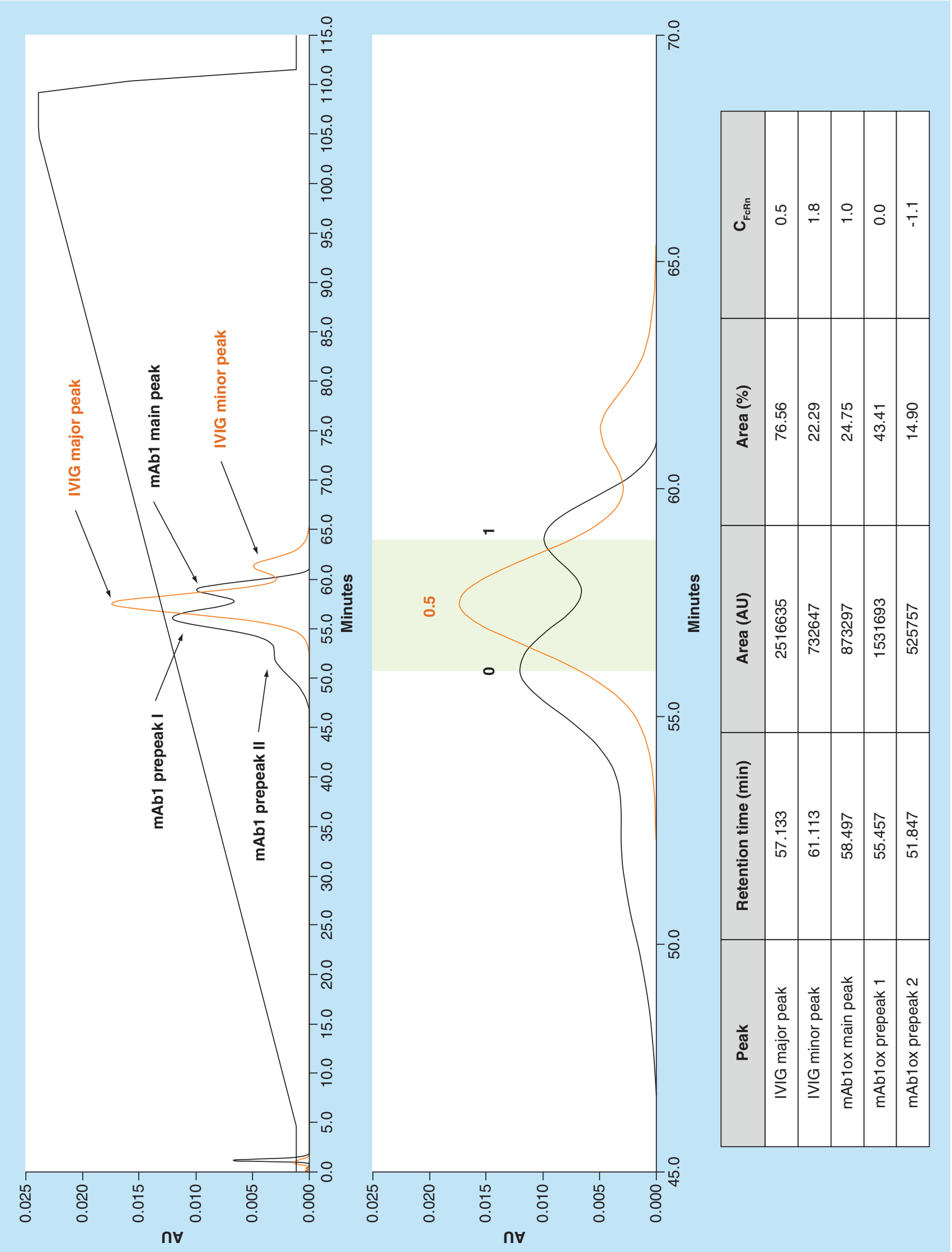


Figure 1. Chromatograms of used standards intravenous immunoglobulin and oxidized monoclonal antibody 1 (see facing page). IVIG (orange chromatogram) elutes as two peaks, one with a low retention time named major peak and one at higher retention time named minor peak (upper panel). Oxidized mAb1 (black chromatogram) elutes with three peaks: prepeak II with a low retention time followed by prepeak I and main peak (previously described in [12]). The gradient of high $\mathrm{pH}$ buffer is shown as a black line. In the lower panel, a zoomed view of the respective peaks is shown and the proposed noncriticality retention time interval between mAb1 prepeak I and main peak is indicated in green.

IVIG: Intravenous immunoglobulin; mAb: Monoclonal antibody.

represent spectroscopically active components of the formulation buffers as well as unbound material. IVIG minor peak elutes with a higher retention time compared with IVIG major peak. Preliminary analysis by size exclusion chromatography indicates that IVIG minor peak represents higher MW species (data not shown). In the middle panel of Figure 1, an enlarged view of the relevant peaks is shown, with assigned $\mathrm{C}_{\mathrm{FcRn}}$ values (calculated according to Equation 1) shown above the respective peaks. The proposed window of noncriticality is indicated in green. The lower panel of Figure 1 lists the most relevant peak data of the standards and demonstrates that system suitability criteria were met with $\mathrm{C}_{\mathrm{FcRn}}$ for IVIG major peak being 0.5 .

\section{Qualification characteristics}

Qualification experiments were carried out according to the procedure described under the 'Materials $\&$ methods' section and key results are summarized in Table 2. Selectivity of the method was demonstrated by injecting mobile phase as well as formulation buffer as sample. No interference was observed in the resulting chromatograms (data not shown). mAb_A was oxidized as described under the 'Materials \& methods' section and used as sample together with nonoxidized material. The resulting chromatograms are shown in Figure 2A. In addition to main peak, prepeak I and prepeak II can be seen in mAb_A oxidized material. No peak in the oxidized sample could be baseline-separated and prepeak II did not show a clear valley toward prepeak I (similar to oxidized $\mathrm{mAb} 1$ shown in Figure 1). Main peak in nonoxidized and oxidized mAb_A gave slightly different $\mathrm{C}_{\mathrm{FcRn}}$ values but were well within the noncriticality window. Prepeak II resulted in a $\mathrm{C}_{\mathrm{FcRn}}$ value of -2.1 and was therefore regarded as potentially critical in terms of $F_{c} R n$ interaction. Based on these results, the method has stability-indicating properties.

The linearity of the method was established by injecting mAb_A three-times at five different levels $(50,75,100,125$ and $150 \%)$ of the nominal amount

\section{Table 2. Summary table of key qualification results.}

Qualification characteristics

Selectivity:

- Interference of mobile phase

- Identification of oxidative stressed species

(stability indicating properties)

Linearity:

- Correlation coefficient $\quad 0.9977$

- Slope

-y-intercept

- Residual sum of squares

Accuracy by recovery:

- Mean recovery (per level)

$-95 \% \mathrm{Cl}$ of mean recovery

Precision/repeatability:

- RSD (per level)

- SD (per level)

Range

Results of selectivity, linearity, accuracy, precision and range are shown.

\section{Qualification results}

No interference observed upon visual evaluation

The method is stability indicating

94193 (area counts/ $\mu \mathrm{g}$ )

-178058 (area counts)

$1.13 \mathrm{E}+10$ (area counts) ${ }^{2}$

$100.3 \%$

$100.0 \pm 1.2 \%$

$0.1-0.6 \%$

$15-45 \mu \mathrm{g} / 50 \mu \mathrm{l}(50-150 \%)$




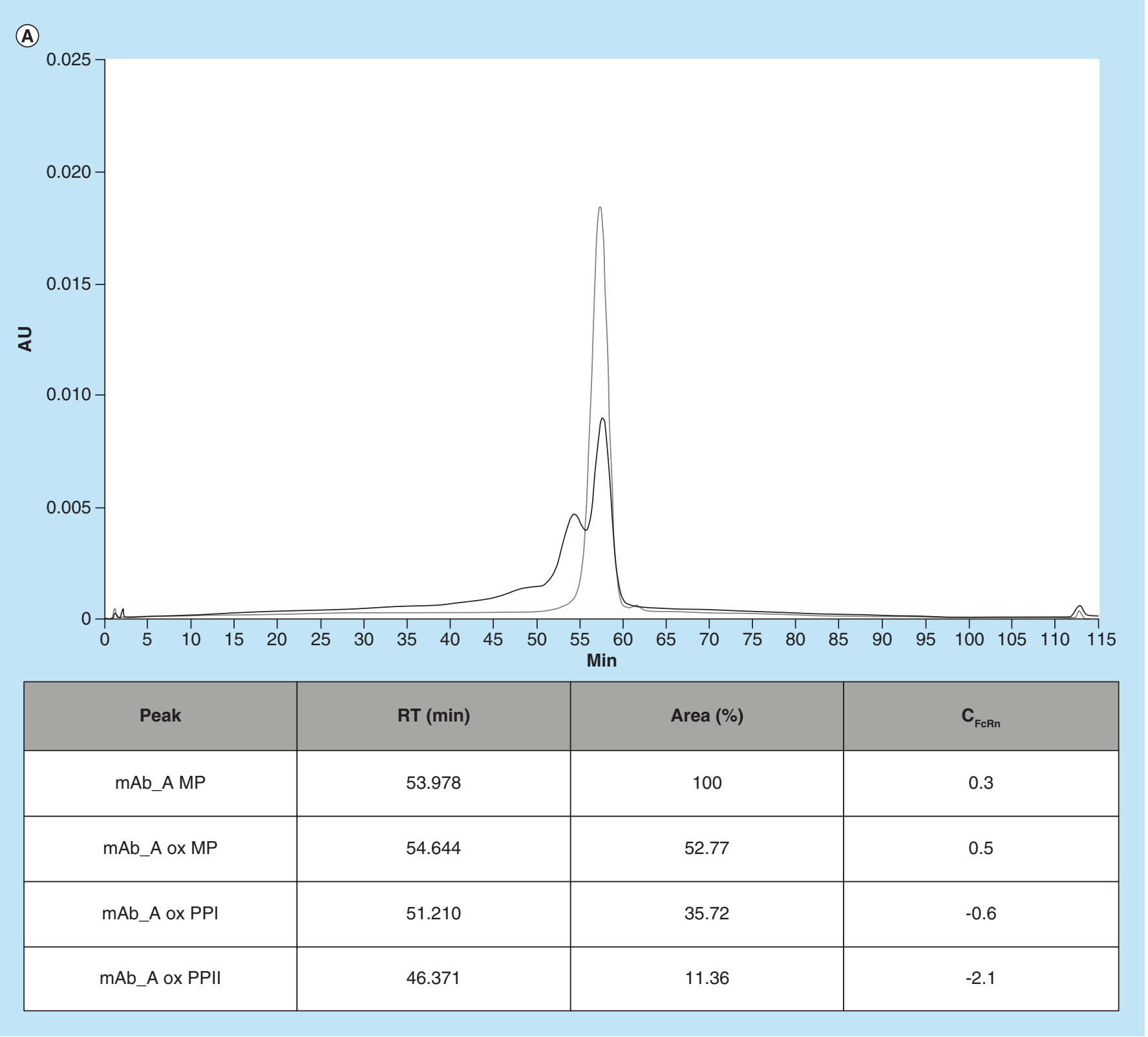

Figure 2. Linearity and robustness results of qualification experiments. Chromatograms of oxidized and nonoxidized mAb_A material (A) and results of linearity (B \& C) as well as robustness (D). (A) Chromatograms of mAb_A (grey line) and oxidized material (black line) are shown. In the lower panel, peak characteristics are listed for main peak, prepeak I and prepeak II. (B) Graphical representation of the linearity results is shown. Error bars are within the size of the data indicators. (C) Retention time versus injected mAb_A amount. (D) Changes in $C_{F C R n}$ depending on $\mathrm{pH}$ of buffer $A / B$. Relative $C_{F C R n}$ values are shown for regular assay conditions (blue bar, $100 \%$ ) and modified assay conditions (orange bars). For parts (B, C \& D), see facing page.

FcRn: Neonatal Fc-receptor; mAb: Monoclonal antibody; MP: Main peak; PPI: Prepeak I; PPII: Prepeak II: RT: Retention time.

of $30 \mu \mathrm{g}$ (see Figure 2B \& Supplementary Table 1 for individual results). Each level was prepared as an independent dilution. The resulting area counts were plotted against the injected protein (in $\mu \mathrm{g}$ ) and linear regression was applied. Linearity could be established with a slope of 94193 area counts/ $\mu \mathrm{g}$ of injected mAb_A. Y-intercept was found at -178058 area counts and correlation coefficient was 0.9977 .
The method is therefore regarded linear in the tested range of $15-45 \mu \mathrm{g}$ of injected protein $/ 50 \mu \mathrm{l}$. Furthermore, with different protein amounts injected, no significant change in retention time was observed in the tested range (Figure $2 \mathrm{C}$ ). $\mathrm{C}_{\mathrm{FcRn}}$ values differed slightly between the different injection levels of mAb_A (see Supplementary Table 1), but were well within the defined noncriticality window. 


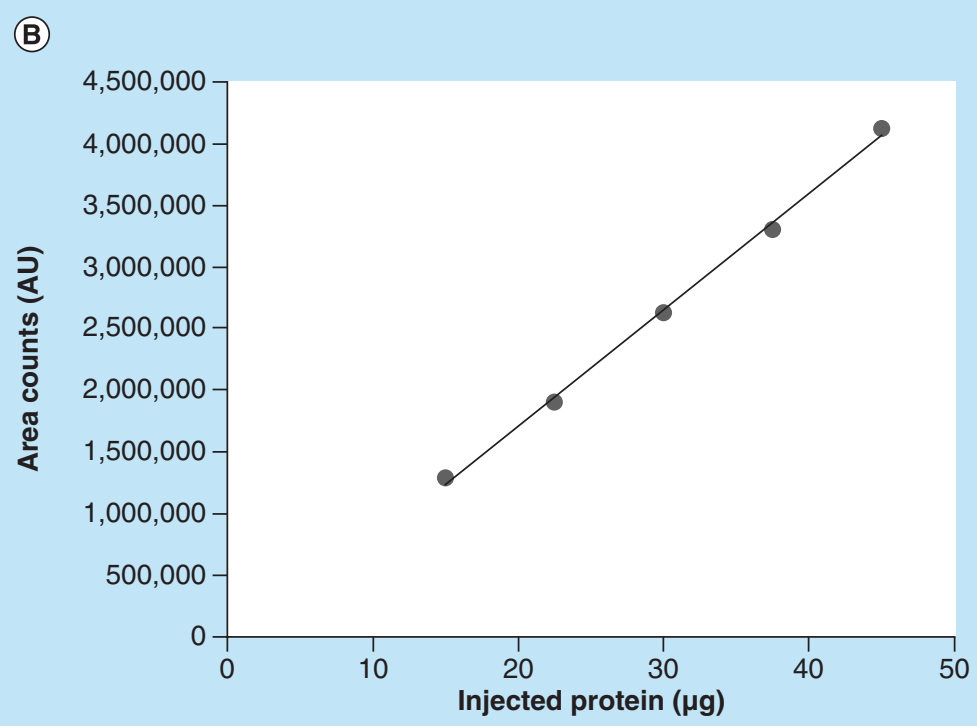

(c)

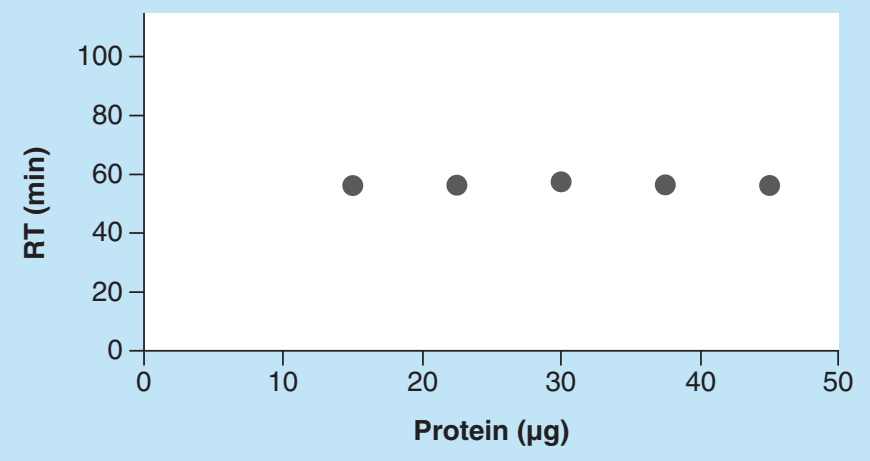

(D)

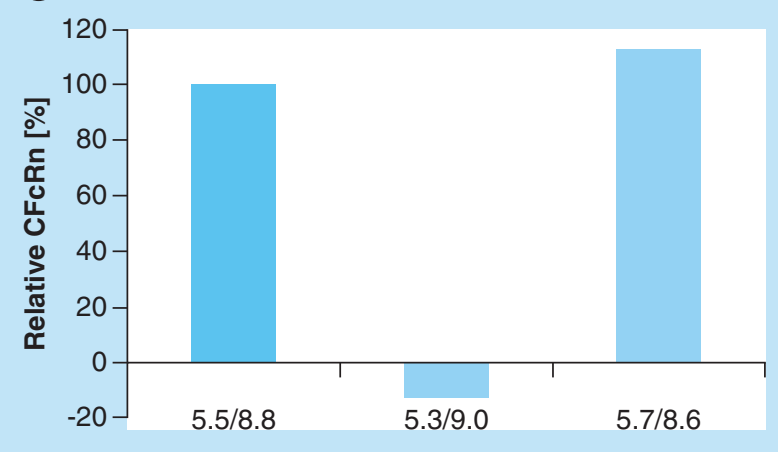

Accuracy of the method could be demonstrated by assessment of recovery parameters. Data from the linearity analysis were used to calculate recovery as:

recovery $=(\%$ area measured $/$ calculated $\%$ area $) * 100 \%$

The mean recovery per level (calculated according to Equation 2) was $100.3 \%$ and the $95 \%$ CI of the mean recovery was $100 \pm 1.2 \%$. The range of mean recoveries was $98-104 \%$. When plotting area measured versus area calculated, it was possible to derive the $95 \%$ CI of the intercept, which was $-1.4244 \pm 247428$ (AU). This well included the origin of the plot and indicates the possibility to extend the current range and determine parameters for LOD and LOQ in future validation experiments. Detailed results are also shown in Supplementary Table 2. Repeatability of the assay was demonstrated using the data of the linearity assessment. The method was shown to be repeatable, with relative SDs per level between 0.1 and $0.6 \%$ (see Supplementary Table 3). For the $100 \%$ level, a relative SD of $0.6 \%$ was found.

To assess the robustness of the method, the $\mathrm{pH}$ of the mobile phase was varied and $\mathrm{C}_{\mathrm{FcRn}}$ of $\mathrm{mAb} \_\mathrm{A}$ was determined. A broader $\mathrm{pH}$ range was used (while using the same chromatographic program outlined in Table 1), with buffer $\mathrm{A}$ at $\mathrm{pH} 5.3$ and buffer $\mathrm{B}$ at $\mathrm{pH}$ 9.0. The resulting $\mathrm{C}_{\mathrm{FcRn}}$ value was $-12.5 \%$ compared with that of mAb_A under standard method conditions. This dramatic shift was not observed for a narrower $\mathrm{pH}$ range, with buffer $\mathrm{A}$ at $\mathrm{pH} 5.7$ and buffer $\mathrm{B}$ at $\mathrm{pH}$ 8.6. Here, an increase to $112.5 \%$ of $\mathrm{C}_{\mathrm{FcRn}_{\mathrm{n}}}$ was observed and is considered moderate (see Figure 2D).

Storage of the mobile phase was evaluated as well. After 2 weeks of storage at room temperature, no change in $\mathrm{pH}$ was observed. The $\mathrm{C}_{\mathrm{FcRn}}$ value for mAb_A was determined with the same buffers at beginning of storage and at the end of the 2 -week period. The relative $\mathrm{C}_{\mathrm{FcRn}}$ value after 2 weeks of storage was found to be $93.4 \%$. Although the observed change was judged to be moderate, we recommend using freshly prepared buffers or a maximum storage of buffers A and B for 1 week.

In the following sections, we aimed to challenge the proposed noncriticality window, by measuring IgG variants where both FcRn binding and in some cases in vivo PKs have previously been evaluated. Differ- 


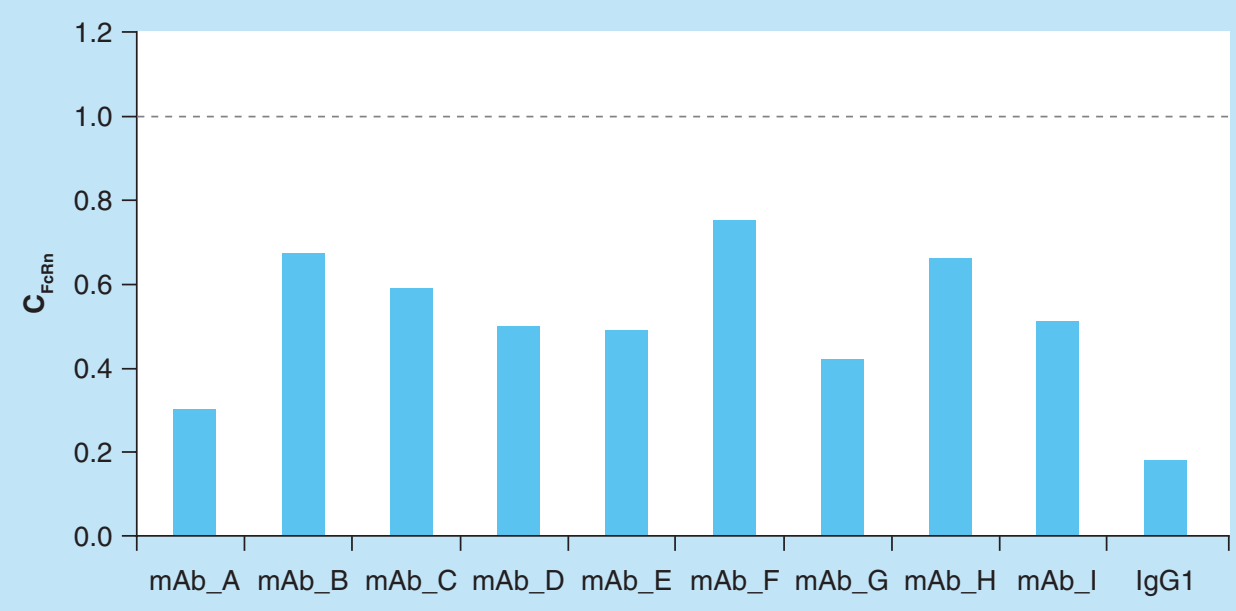

\begin{tabular}{|l|l|}
\hline Sample & C FcRn $_{\text {FAb_A }}$ \\
\hline mAb_B & 0.30 \\
\hline mAb_C & 0.67 \\
\hline mAb_D & 0.59 \\
\hline mAb_E & 0.50 \\
\hline mAb_F & 0.75 \\
\hline mAb_G & 0.42 \\
\hline mAb_H & 0.66 \\
\hline mAb_I & 0.51 \\
\hline IgG1 & 0.18 \\
\hline
\end{tabular}

Figure 3. $C_{\mathrm{FcRn}}$ values of ten monoclonal IgG1 antibodies. Ten IgG1 antibodies were used in the described method. The resulting $\mathrm{C}_{\mathrm{FCRn}}$ values of all antibodies are within the noncriticality window. Sample 'IgG1' is identical to the one in Figure 4 (see also the 'Materials \& methods' section).

FcRn: Neonatal Fc-receptor; mAb: Monoclonal antibody.

ent IgG1 mAbs, IgG-subtypes, glycoengineered IgG1 antibodies as well as established mutants were tested.

\section{IgG1 mAbs}

In order to assure a broad applicability of the proposed noncriticality interval, we used ten different monoclonal IgG1-based antibodies with the described FcRn affinity chromatographic method (see Figure 3). Interestingly, all $\mathrm{C}_{\mathrm{FcRn}}$ values were within the proposed noncriticality window and were evaluated as not potentially critical in terms of FcRn-dependent clearance. For many of these antibodies, clinical and nonclinical data are available (data not shown), which demonstrate a regular in vivo serum half-life as would be expected for an IgG1 antibody.

\section{Analysis of different IgG subtypes}

The in vivo half-life of human IgG subtypes has been well established in the past. We, therefore, used com- mercially available IgG1, IgG2, IgG3 and IgG4 for FcRn affinity chromatography to test the applicability of the described noncriticality window (see Figure 4). Interestingly IgG1, IgG2 and IgG4 gave similar $\mathrm{C}_{\mathrm{FcRn}}$ values of $0.18,0.34$ and 0.10 , respectively. These subtypes were thus well within the predefined noncriticality window. IgG3, on the other hand, resulted in a significantly different $\mathrm{C}_{\mathrm{FcRn}}$ value of 1.13 and was therefore regarded as potentially critical in terms of FcRn-dependent clearance (compared with IgG1 subtype). These results are in line with the reported short serum halflife of the IgG3 subtype of approximately 1 week versus 4 weeks for other IgG subtypes [25], but are further outlined in the 'discussion' section.

\section{Analysis of in vitro glycoengineered mAbs}

Several studies have investigated the effect of Fc-glycans on FcRn binding and FcRn-dependent clearance [23,2630]. Whereas a difference in FcRn binding could be

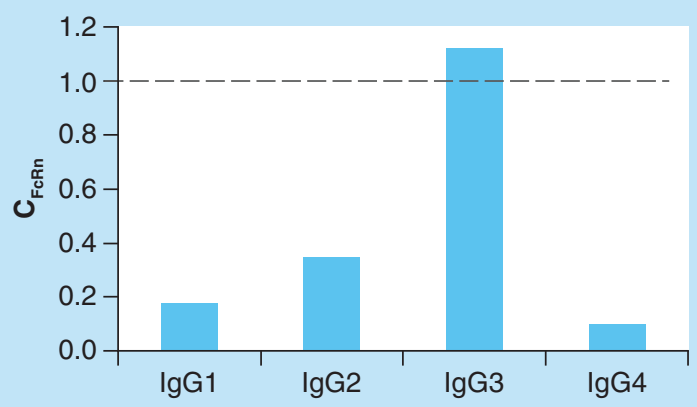

\begin{tabular}{|c|c|}
\hline Sample & $\mathbf{C}_{\mathrm{FcRn}}$ \\
\hline $\operatorname{lgG} 1$ & 0.18 \\
\hline $\lg \mathrm{G} 2$ & 0.34 \\
\hline $\lg \mathrm{G} 3$ & 1.13 \\
\hline $\operatorname{lgG} 4$ & 0.10 \\
\hline
\end{tabular}

Figure 4. IgG subtypes during neonatal Fc-receptor affinity chromatography. Different IgG subtypes result in different $\mathrm{C}_{\mathrm{FcRn}}$ values, with IgG3 being outside the noncriticality window.

FcRn: Neonatal Fc-receptor. 
(A)

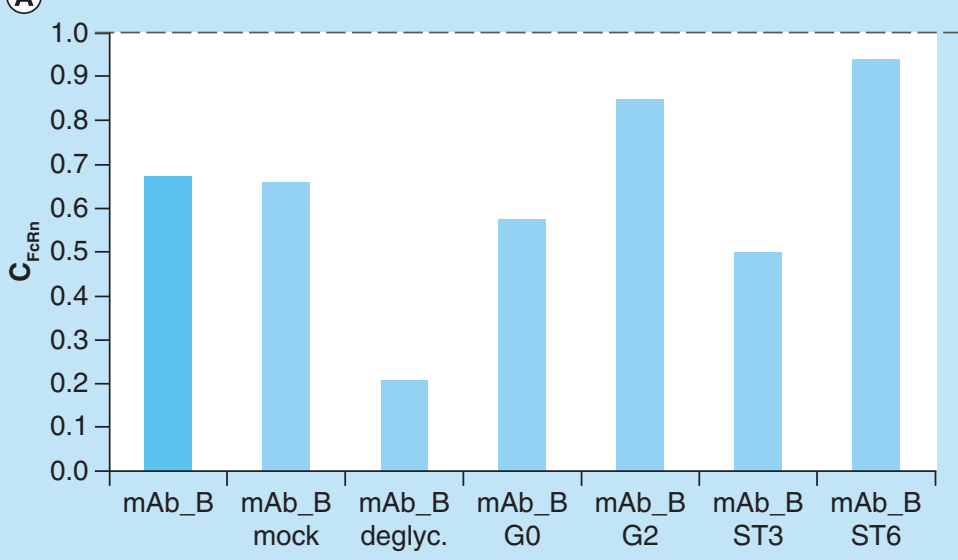

(B)

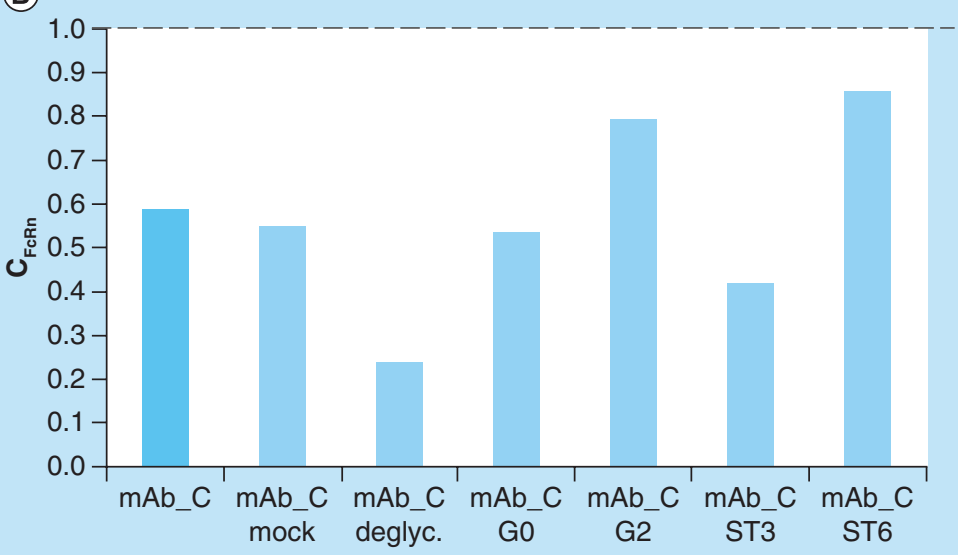

\begin{tabular}{|l|l|}
\hline \multicolumn{1}{|c|}{ Sample } & C $_{\text {FcRn }}$ \\
\hline mAb_B & 0.67 \\
\hline mAb_B mock & 0.66 \\
\hline mAb_B deglyc. & 0.21 \\
\hline mAb_B G0 & 0.58 \\
\hline mAb_B G2 & 0.85 \\
\hline mAb_B ST3 & 0.50 \\
\hline mAb_B ST6 & 0.94 \\
\hline
\end{tabular}

\begin{tabular}{|l|l|}
\hline \multicolumn{1}{|c|}{ Sample } & ${\text { C }{ }_{\text {FcRn }}}$ \\
\hline mAb_C & 0.59 \\
\hline mAb_C mock & 0.55 \\
\hline mAb_C deglyc. & 0.24 \\
\hline mAb_C G0 & 0.54 \\
\hline mAb_C G2 & 0.80 \\
\hline mAb_C ST3 & 0.42 \\
\hline mAb_C ST6 & 0.86 \\
\hline
\end{tabular}

Figure 5. Different glycoform-containing monoclonal antibodies during neonatal Fc-receptor affinity chromatography. $(A) C_{F C R n}$ values of mAb_B, an IgG1-type antibody with regular CHO-derived Fc-glycans, which were glycoengineered in vitro to highly enrich different glycoforms. (B) $C_{F C R n}$ values of $\mathrm{mAb} C$, an IgG1-type antibody, which was produced with a highly enriched proportion of bisecting and afucosylated Fc-glycan. $\mathrm{mAb} C \mathrm{C}$ was glycoengineered in vitro in the same way as mAb_B. Deglyc.: Deglycosylated; FcRn: Neonatal Fc-receptor; G0: Degalactosylated; G2: Galactosylated; mAb: Monoclonal antibody; ST3: Alpha 2,3 sialydated; ST6: Alpha 2,6 sialydated.

shown for several glycoforms [23], a significant change on FcRn-dependent in vivo clearance could not be demonstrated [26]. In order to challenge the described limits of the noncriticality window, two IgG1-type antibodies mAb_B and mAb_C were enzymatically IVGE. $\mathrm{mAb} \_\mathrm{B}$ is a regular CHO-culture derived antibody with a typical glycoprofile in its starting material, whereas mAb_C was produced in a modified $\mathrm{CHO}$ cell line and contains high levels $(\sim 70 \%)$ of bisecting, afucosylated Fc-glycans in its starting material. We generated enzymatically IVGE forms (see the 'Materials \& methods' section) and perfomed FcRn chromatography together with a mock control (IVGE was performed without addition of respective enzyme; see Figure 5A \& B). Of the enzymatically modified samples, we tested deglycosylated (deglyc.), degalactosylated (G0), galactosylated (G2), alpha 2,3 sialydated (ST3) and alpha 2,6 sialydated (ST6) material of mAb_B and mAb_C.

Interestingly, for both $\mathrm{mAb} \_\mathrm{B}$ and $\mathrm{mAb} \_\mathrm{C}$, similar trends in terms of $\mathrm{C}_{\mathrm{FcRn}}$ were observed. Overall, all samples were within the proposed noncriticality window and would therefore not be regarded as potentially critical in terms of FcRn-dependent clearance. Starting material and mock control resulted in similar $\mathrm{C}_{\mathrm{FcRn}}$ values, whereas deglycosylated material resulted in significantly lower $\mathrm{C}_{\mathrm{FcRn}}$ values. Removal of terminal galactose (G0) resulted in similar $\mathrm{C}_{\mathrm{FcRn}}$ values compared with starting material, whereas $\mathrm{C}_{\mathrm{FcRn}}$ of fully galactosylated material (G2) was slightly increased. Interestingly, alpha 2,3 sialydated material (ST3) had a lower $\mathrm{C}_{\mathrm{FcRn}}$ value compared with starting material, whereas alpha 2,6 sialydated material had a comparably higher $\mathrm{C}_{\mathrm{FcRn}}$ value. Taken together, all glycoengineered samples of both mAb_B 


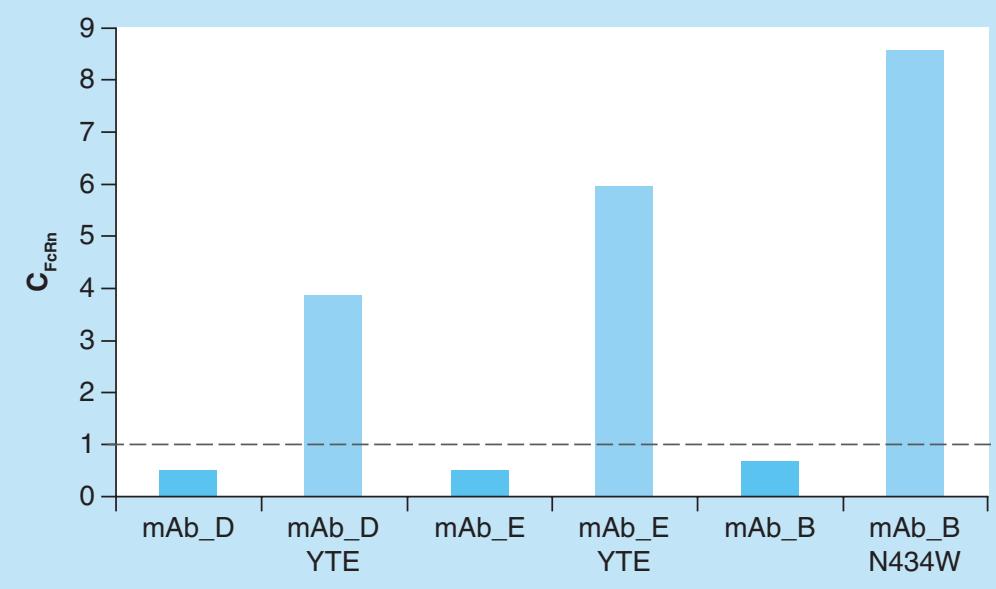

\begin{tabular}{|c|c|}
\hline Sample & C $_{\mathrm{FcRn}}$ \\
\hline mAb_D & 0.50 \\
\hline mAb_DYTE & 3.87 \\
\hline mAb_E & 0.49 \\
\hline mAb_EYTE & 5.97 \\
\hline mAb_B & 0.67 \\
\hline mAb_B N434W & 8.57 \\
\hline
\end{tabular}

Figure 6. Neonatal Fc-receptor affinity chromatography of IgG1 and mutants YTE and N434W. Wild-type antibodies mAb_D, mAb_E and $\mathrm{mAb}$ _B result in noncritical $C_{\mathrm{FcRn}}$ values, whereas mutants $\mathrm{YTE}$ and $\mathrm{mAb}$ _B N434W would be regarded as potentially critical based on their $C_{\mathrm{FCRn}}$ value.

FcRn: Neonatal Fc receptor.

and $\mathrm{mAb}$ _C eluted within the noncriticality window. The presented results for deglycosylated IgG antibodies eluting within the noncriticality window are in line with results from previous in vivo studies confirming no change in PK for aglycosylated antibodies [26,27].

\section{Analysis of IgG1 mutants}

In numerous previous studies, the Fc-portion of IgG1type antibodies has been subjected to targeted and nontargeted mutagenesis to influence the interaction with FcRn (see e.g., [5,17,24,31-32]). The triple mutant M252Y, S254T, T256E (numbering according to Kabat [33]) was reported to have extended serum halflife [32], through optimized interaction with FcRn [34]. On the other hand, Yeung et al. report two mutants N434A and N434W with increased binding to FcRn, albeit N434W displays a serum half-life similar to wild-type IgG1, whereas N434A resulted in extended serum half-life [5]. FcRn affinity chromatography of both mAb_D and mAb_E (both IgG1 antibodies) resulted in very similar noncritical $\mathrm{C}_{\mathrm{FcRn}}$ values of 0.5 and 0.49 , respectively (Figure 6). However, their YTE mutants, mAb_D YTE and mAb_E YTE, resulted in very different $\mathrm{C}_{\mathrm{FcRn}}$ values of 3.87 and 5.97 , respectively and would be regarded as potentially critical in terms of FcRn-dependent clearance. Whereas this is in line with reports from the literature describing the increased serum half-life of YTE mutants compared with wild-type IgG1 [32], the similar $\mathrm{C}_{\mathrm{FcRn}}$ values of the parent IgGs and the strong difference of the respective YTE mutants were surprising. Interestingly, mAb_B N434W had an even higher $\mathrm{C}_{\mathrm{FcRn}}$ value of 8.57 and would therefore be regarded as being potentially critical in terms of FcRn-dependent clearance. Nevertheless, as has been reported previously, this mutant shows wild-type like clearance in vivo [5].

\section{Discussion}

The interaction of IgG-type antibodies with FcRn is regarded the most critical determinant in terms of serum half-life and therefore considered to be important with regard to PKs of IgG-based biotherapeutics. The mechanisms of the interaction should be reflected in a concise in vitro assay strategy during development of such therapeutics. Data evaluation which is guided by limits derived from samples with a thoroughly investigated and biologically relevant in vivo behavior should be established.

In this study, we report our current efforts to establish these limits in an FcRn affinity chromatographic method, which accounts for the $\mathrm{pH}$-dependent interaction of IgG-type antibodies with FcRn. We suggest a conservative noncriticality window, whose boundaries are defined by standards previously identified as noncritical in terms of FcRn-mediated in vivo clearance [18]. Furthermore we established a system suitability criterion using IVIG as an additional standard. The method could be successfully qualified and therefore met the minimal technical requirements of a suitable in vitro method. FcRn chromatography is currently intended for use during extended characterization only. Extending the usage of the methodology would require a deep understanding of how findings in vivo correlate to in vitro data and would additionally require a full validation (discussed in the 'Future perspective' section). 
Currently, the method itself is considered novel [18] compared with the aforementioned SPR-based methods [19] or other methods for interaction analysis of IgG with FcRn (see e.g., [35]). Therefore, experience with the method itself and the interpretation of results are still limited. Kelly et al. recently published a study, where Fabmediated nonspecific effects might contribute to clearance and also might influence the results observed during FcRn affinity chromatography by nonspecific binding to the column matrix [36]. This is currently addressed in an ongoing study and preliminary results indicate no unspecific Fab-charge-mediated matrix interaction. Results from Wang et al. suggest that Fab charges cannot only influence the outcome of FcRn affinity chromatography but at the same time influence the outcome of SPR-based assays, depending on the chosen setup [19]. Correlations between FcRn affinity chromatography results of antibodies with differently charged Fab fragments and their in vivo $\mathrm{PK}$ were already established previously [4] and recent hydrogen-deuterium exchange (HDX) data supplemented by FcRn affinity chromatography data furthermore indicate that both interactions contribute to binding [37].

The results reported here on the $\mathrm{C}_{\mathrm{FcRn}}$ values of different $\operatorname{IgG}$ subtypes appear to be in line with reported serum half-life in humans, with $\operatorname{IgG} 1, \operatorname{IgG} 2$ and IgG4 having a long serum half-life and IgG3 having a significantly shorter serum half-life [25]. Still, recent reports identified a competition between IgG subtypes in the early endosome to be responsible for the short serum half-life of IgG3 [6]. This is due to an arginine at position 435 in IgG3 instead of histidine as in other IgG subtypes. Arginine at this position leads to a stronger binding of IgG3 at a more neutral $\mathrm{pH}$ compared with histidine at this position in IgG1. Although this competition is not reflected in the current method, the method is able to indicate this slight difference in dissociation due to the applied pH gradient and the established noncriticality window.

Previous reports have identified the Fc-glycans to have little influence on FcRn binding [23] and deglycosylation was shown not to influence FcRn-dependent clearance [26]. We used two different IgG1-based antibodies, one with a regular glycopattern and one with a modified (bisecting and afucosylated) glycopattern. We then modified the glycostructures in vitro and generated deglycosylated as well as several highly enriched glycostructures. Interestingly, all these samples resulted in $\mathrm{C}_{\mathrm{FcRn}}$ values within the noncriticality window. These results therefore further support the validity of these boundaries and the suitability of the method.

Mutants that possess a different interaction profile with FcRn have been thoroughly investigated in the past, for example, for the aforementioned YTE-mutant interaction analysis [24], in vivo clearance [32] and structural studies [38] have been performed. Due to the wealth of information available, these mutants are well suited to assess new assays such as the one reported here. The results obtained in this study using YTE mutants are well in line with the literature data available. The high $\mathrm{C}_{\mathrm{FcRn}}$ value of 3.87 would identify the YTE mutant as potentially critical in terms of FcRn interaction, which is well supported by the studies mentioned (see the 'Results' section). An interesting case is the mutation N434W, where a significantly stronger FcRn binding was reported, albeit without a change in in vivo clearance compared with wild-type IgG1 [5]. This variant had the highest $\mathrm{C}_{\mathrm{FcRn}}$ value observed of 8.57. Since the variant has wild-type like clearance but changes in, for example, tissue distribution and/or other PK parameters are currently unknown, the implications of the results shown here cannot be discussed appropriately. These results will have to be addressed in a combination of future in vitro and in vivo studies.

\section{Future perspective}

The future use of FcRn affinity chromatography has the potential to complement other interaction methods such as SPR-based assays [19]. Development of an integrated analytical assay strategy will aim to comprehensively assess the complex FcRn-dependent clearance mechanisms. Furthermore, we expect to see this methodology being applied in combination with many other characterization technologies, such as native mass spectrometry and others $[20,21]$. Screening of early candidates of therapeutic antibodies would be an additional potential use of the method. As method understanding will increase, it might be possible to extend the use of FcRn chromatography beyond the purpose of extended characterization. This would require a full (antibody specific) validation of the method including parameters like intermediate precision, LOD, LOQ as well as a detailed understanding of impurities and isolated heterogeneities (e.g., different M252 oxidation states). Eventually, affinity chromatography might be extended to other Fc-receptors, with the knowledge gained from development of the FcRn methods to cover other complex interaction models. Such prototypes have already been tested in the past [39] and will be developed further in the future. Nevertheless, orthogonal methods and in vivo data will have to continuously challenge these analytical methods but also have the potential to drive their development.

\section{Financial \& competing interests disclosure}

All authors are employees of Roche. All research materials were funded by Roche. The authors have no other relevant 
affiliations or financial involvement with any organization or entity with a financial interest in or financial conflict with the subject matter or materials discussed in the manuscript apart from those disclosed.

No writing assistance was utilized in the production of this manuscript.

\section{Ethical conduct of research}

The authors state that they have obtained appropriate institutional review board approval or have followed the principles outlined in the Declaration of Helsinki for all human or animal experimental investigations. In addition, for investigations in- volving human subjects, informed consent has been obtained from the participants involved.

\section{Open access}

This work is licensed under the Attribution-NonCommercialNoDerivatives 4.0 Unported License. To view a copy of this license, visit http://creativecommons.org/licenses/by-nc-nd/4.0/

\section{Supplementary data}

To view the supplementary data that accompany this paper, please visit the journal website at: www.future-science.com/ doi/full/10.4155/bio-2017-0109

\section{Executive summary}

\section{Background}

- The neonatal Fc-receptor ( $F C R n)$ mediates long serum half-life of IgG-type antibodies. Antibodies are taken up by cells unspecifically and can bind to $\mathrm{FcRn}$ in a $\mathrm{pH}$-dependent manner in early endosomes preventing lysosomal degradation and are reshuffled into circulation.

Results \& discussion

- We demonstrate the qualification of an FcRn affinity chromatographic method and establish a noncriticality window, which allows the assessment of mAb samples with respect to their pH-dependent FcRn interaction.

- In order to place our results in a biological context and to challenge this noncriticality window, we analyze different IgG-type antibodies, IgG subtypes, glycoforms as well as well-established mutants.

\section{Conclusion}

- The assay was successfully qualified and the tested samples behaved according to expectations derived from previous studies. It will be a future task to further challenge and derive a deeper understanding of the method and to follow its applicability in both research and development.

\section{References}

Papers of special note have been highlighted as: $\bullet$ of interest; •• of considerable interest

1 Pyzik M, Rath T, Lencer WI, Baker K, Blumberg RS. FcRn: the architect behind the immune and nonimmune functions of IgG and albumin. J. Immunol. 194(10), 4595-4603 (2015).

2 Unverdorben F, Richter F, Hutt M et al. Pharmacokinetic properties of $\mathrm{IgG}$ and various $\mathrm{Fc}$ fusion proteins in mice. MAbs 8(1), 120-128 (2016).

3 Kontermann RE. Half-life extended biotherapeutics. Expert Opin. Biol. Ther. 16(7), 903-915 (2016).

4 Schoch A, Kettenberger H, Mundigl O et al. Chargemediated influence of the antibody variable domain on FcRn-dependent pharmacokinetics. Proc. Natl Acad. Sci. USA 112(19), 5997-6002 (2015).

5 Yeung YA, Leabman MK, Marvin JS et al. Engineering human $\operatorname{IgG1}$ affinity to human neonatal $\mathrm{Fc}$ receptor: impact of affinity improvement on pharmacokinetics in primates. J. Immunol. 182(12), 7663-7671 (2009).

-• $\quad$ Outlines the in vitro neonatal Fc-receptor ( $\left.F_{c} R n\right)$ interaction of several mutants and their in vivo pharmacokinetics.

6 Stapleton NM, Andersen JT, Stemerding AM et al. Competition for $\mathrm{FcRn}$-mediated transport gives rise to short half-life of human $\operatorname{IgG} 3$ and offers therapeutic potential. Nat. Commun. 2, 599 (2011).
7 Finkler C, Krummen L. Introduction to the application of $\mathrm{QbD}$ principles for the development of monoclonal antibodies. Biologicals 44(5), 282-290 (2016).

8 Kepert JF, Cromwell M, Engler $\mathrm{N}$ et al. Establishing a control system using QbD principles. Biologicals 44(5), 319-331 (2016).

9 Alt N, Zhang TY, Motchnik P et al. Determination of critical quality attributes for monoclonal antibodies using quality by design principles. Biologicals 44(5), 291-305 (2016).

10 Neuber T, Frese K, Jaehrling J et al. Characterization and screening of $\operatorname{IgG}$ binding to the neonatal Fc receptor. MAbs 6(4), 928-942 (2014).

11 Abdiche YN, Yeung YA, Chaparro-Riggers J et al. The neonatal $F_{c}$ receptor $\left(F_{c} R n\right)$ binds independently to both sites of the IgG homodimer with identical affinity. MAbs 7(2), 331-343 (2015).

12 Ternant D, Arnoult C, Pugniere M et al. IgG1 allotypes influence the pharmacokinetics of therapeutic monoclonal antibodies through FcRn binding. J. Immunol. 196(2), 607-613 (2016).

13 Gao X, Ji JA, Veeravalli K et al. Effect of individual Fc methionine oxidation on FcRn binding: Met252 oxidation impairs FcRn binding more profoundly than Met 428 oxidation. J. Pharm. Sci. 104(2), 368-377 (2015).

14 Gurbaxani B, Dela Cruz LL, Chintalacharuvu K, Morrison SL. Analysis of a family of antibodies with different half- 
lives in mice fails to find a correlation between affinity for FcRn and serum half-life. Mol. Immunol. 43(9), 1462-1473 (2006).

15 Roopenian DC, Christianson GJ, Sproule TJ. Human $\mathrm{FcRn}$ transgenic mice for pharmacokinetic evaluation of therapeutic antibodies. Methods Mol. Biol. 602, 93-104 (2010).

16 Latvala S, Jacobsen B, Otteneder MB, Herrmann A, Kronenberg S. Distribution of FcRn across species and tissues. J. Histochem. Cytochem. 65(6), 321-333 (2017).

17 Schlothauer T, Rueger P, Stracke JO et al. Analytical FcRn affinity chromatography for functional characterization of monoclonal antibodies. MAbs 5(4), 576-586 (2013).

-. Publication that initially established FcRn affinity chromatography.

18 Stracke J, Emrich T, Rueger P et al. A novel approach to investigate the effect of methionine oxidation on pharmacokinetic properties of therapeutic antibodies. MAbs 6(5), 1229-1242 (2014).

-• Used FcRn affinity chromatography to analyze the contribution of different oxidized IgG methionines to FcRn binding and in vivo pharmacokinetics.

19 Wang X, Mckay P, Yee LT et al. Impact of SPR biosensor assay configuration on antibody: neonatal $\mathrm{F}_{\mathrm{C}}$ receptor binding data. MAbs 9 (2), 319-332 (2017).

- In this study, the possible pitfalls of surface plasmon resonance setups are identified with support of FcRn affinity chromatography.

20 Gahoual R, Heidenreich AK, Somsen GW et al. Detailed characterization of monoclonal antibody receptor interaction using affinity liquid chromatography hyphenated to native mass spectrometry. Anal. Chem. 89(10), 5404-5412 (2017).

21 Haberger M, Heidenreich AK, Schlothauer T et al. Functional assessment of antibody oxidation by native mass spectrometry. MAbs 7(5), 891-900 (2015).

- Demonstrates the combination of FcRn affinity chromatography with other technologies.

22 Chammas R, Thomann M, Schlothauer T et al. In vitro glycoengineering of $\mathrm{IgG} 1$ and its effect on $\mathrm{FC}$ receptor binding and ADCC activity. PLoS ONE 10(8), e0134949 (2015).

23 Karagiannis SN, Dashivets T, Thomann M et al. Multiangle effector function analysis of human monoclonal $\mathrm{IgG}$ glycovariants. PLoS ONE 10(12), e0143520 (2015).

24 Dall'acqua WF, Kiener PA, Wu H. Properties of human IgG1s engineered for enhanced binding to the neonatal Fc receptor (FcRn). J. Biol. Chem. 281(33), 23514-23524 (2006).

25 Morell A, Terry WD, Waldmann TA. Metabolic properties of IgG subclasses in man. J. Clin. Invest. 49(4), 673-680 (1970).

26 Leabman MK, Meng YG, Kelley RF, Deforge LE, Cowan KJ, Iyer S. Effects of altered Fc $\gamma \mathrm{R}$ binding on antibody pharmacokinetics in cynomolgus monkeys. MAbs 5(6), 896-903 (2014).
27 Liu L, Stadheim A, Hamuro L et al. Pharmacokinetics of IgG1 monoclonal antibodies produced in humanized Pichia pastoris with specific glycoforms: a comparative study with CHO produced materials. Biologicals 39 (4), 205-210 (2011).

28 Tao MH, Morrison SL. Studies of aglycosylated chimeric mouse-human IgG. Role of carbohydrate in the structure and effector functions mediated by the human IgG constant region. J. Immunol. 143(8), 2595-2601 (1989).

29 Nose M, Wigzell H. Biological significance of carbohydrate chains on monoclonal antibodies. Proc. Natl Acad. Sci. USA 80 (21), 6632-6636 (1983).

30 Souders CA, Nelson SC, Wang Y, Crowley AR, Klempner MS, Thomas W, Jr. A novel in vitro assay to predict neonatal Fc receptor-mediated human IgG half-life. MAbs 7(5), 912-921 (2015).

31 Shields RL, Namenuk AK, Hong K et al. High resolution mapping of the binding site on human IgG1 for Fcgamma RI, Fcgamma RII, Fcgamma RIII, and FcRn and design of IgG1 variants with improved binding to the Fcgamma $R$. J. Biol. Chem. 276(9), 6591-6604 (2000).

32 Robbie GJ, Criste R, Dall'Acqua WF et al. A novel investigational Fc-modified humanized monoclonal antibody, motavizumab-YTE, has an extended half-life in healthy adults. Antimicrob. Agents Chemother. 57(12), 6147-6153 (2013).

33 Kabat EA, Wu T, Perry H, Gottesman K, Foeller C. Sequences of proteins of immunological interest. NIH Publication No. 91-3242 (1991).

https://searchworks.stanford.edu/view/2706015

34 Oganesyan V, Mazor Y, Yang C et al. Structural insights into the interaction of human IgG1 with FcgammaRI: no direct role of glycans in binding. Acta Crystallogr. D Biol. Crystallogr. 71(Pt 11), 2354-2361 (2015).

35 Lu Y, Vernes JM, Chiang N et al. Identification of $\operatorname{IgG}(1)$ variants with increased affinity to FcgammaRIIIa and unaltered affinity to FcgammaRI and FcRn: comparison of soluble receptor-based and cell-based binding assays. J. Immunol. Methods 365(1-2), 132-141 (2011).

36 Kelly RL, Yu Y, Sun T et al. Target-independent variable region mediated effects on antibody clearance can be FcRn independent. MAbs 8(7), 1269-1275 (2016).

37 Jensen PF, Schoch A, Larraillet V et al. A two-pronged binding mechanism of IgG to the neonatal $F_{c}$ receptor controls complex stability and IgG serum half-life. Mol. Cell. Proteomics 16(3), 451-456 (2017).

38 Oganesyan V, Damschroder MM, Cook KE et al. Structural insights into neonatal Fc receptor-based recycling mechanisms. J. Biol. Chem. 289(11), 7812-7824 (2014).

39 Thomann M, Schlothauer T, Dashivets T et al. In vitro glycoengineering of $\mathrm{IgG1}$ and its effect on $\mathrm{Fc}$ receptor binding and ADCC activity. PLoS ONE 10(8), e0134949 (2015).

- Demonstrates the applicability of affinity chromatography for another Fc receptor. 